\title{
From haemochromatosis to liver transplant
}

This patient describes the limitations of being on a waiting list for transplant and his experiences after surgery

\author{
Mike Davis patient ${ }^{1}$, Phaedra Maria Tachtatzis consultant hepatologist ${ }^{2}$ \\ 'Blackpool, Lancashire, UK; ${ }^{2}$ The Liver Transplant Unit, St James's University Hospital, Leeds LS9 7TF, UK
}

This is one of a series of occasional articles by patients about their experiences that offer lessons to doctors.

My journey began in 2003 when my doctor spotted a slight abnormality in routine blood tests during monitoring of my type 2 diabetes. I was referred to a gastroenterologist who, after further investigations, diagnosed haemochromatosis. Over the next few months I had venesection on a weekly basis and my condition stabilised, with ferritin levels slightly below normal. I subsequently had the occasional review and in 2009 I experienced a gastrointestinal bleed caused by portal hypertension. Investigations indicated that I had cirrhosis and this would be monitored.

In early 2011 I combined a working visit to Mexico with a holiday and before going I had routine scans. I was told that I would hear if there were any problems.

On my return in the early hours of 14 April I listened to increasingly urgent recorded messages for me to contact Blackpool Victoria Hospital. Eventually, consultations with the gastroenterologist confirmed that I had a small liver tumour and that I would need an urgent referral to the liver unit at St James's University Hospital in Leeds. My appointment was on 3 May.

The diagnosis was a shock and I spent the following nine months somewhat emotionally numb. Consultations came and went over the next few weeks, confirming that I needed a transplant and that I would be recommended to go on the transplant list. Waiting for the results of the meeting was tense- the decision was delayed twice - and there was no clear indication of what the criteria for selection might be. I had three visits to St James's hospital during May, including further computed tomography and the recommendation that I undergo chemoembolisation.

Over the next few months I was admitted for chemoembolisation; the first was trouble-free and I was discharged the next day. On the second occasion, in September 2011, the consultant was unable to find the tumour and although further investigation indicated that it was still there, it had shrunk considerably. The consultation shortly after this was very reassuring; I felt well and had no overt symptoms, apart from some brief visual disturbance that I put down to stress related migraine, which I had experienced once or twice before. The consultant and I explored the possibility of briefly taking me off the transplant list to allow a short break abroad. The requirement to be within three hours travel time of Leeds was one of the most frustrating elements of my time on the waiting list.

A couple of weeks after these discussions the telephone rang at about $1035 \mathrm{pm}$. It was the transplant coordinator at St James's hospital who told me that there was a potentially suitable liver and that I should get to the hospital as soon as possible. An uneventful drive got me there at $1230 \mathrm{am}$. After some tests there was a short wait before the transplant nurse came to say that the liver was not viable. The drive home was a strange journey - a mixture of disappointment and relief.

The possibility that I was close to the top of the list made my family and I rethink about travel. Although there had been apparent openness in discussions with consultants, there had been no clear explanation of how decisions were made about transplant: the UKELD (United Kingdom end stage liver disease) score was never referred to, for example. Clearly I met the criteria.

My family and I decided to restrict our travel to the United Kingdom, within three hours travel time of Leeds. We booked to spend three days in Chester in December and were on our second day when the phone rang at about $1030 \mathrm{pm}$ and I was told that there was a good chance of a liver match and I should get to St James's hospital as soon as possible. Because of motorway closures and poor road signs, a journey that should have taken 90 minutes took twice as long.

The next few hours were a bit of a blur. There were tests and reassurances, and two beds were thoughtfully pushed together in a bay that had been shut for deep cleaning. We were told that a decision about the viability of the liver would be made in the morning. We slept little and spent a desultory morning wondering what was going to happen. The anaesthetist came 
and reassured us about an impending decision, but by late morning I was anticipating a return journey home on the M62. A little after midday, however, I was told that the operation was going ahead. My recollection at this point becomes hazy: I remember a trip along corridors and being in the anteroom to the theatre in conversation with the anaesthetist, and then ...

I came around in the intensive care unit at $600 \mathrm{pm}$, complaining of pain and finding it particularly hard to cough. The next few days were characterised by long periods of drifting in and out of morphine induced sleep. As the effect of this lessened and I began to recover from the anaesthetic, I had an unexpected (but possibly typical?) reaction. As I became more wakeful during the day, my sleep pattern at night was disturbed by visual and auditory hallucinations: time was distorted and massively elongated - the bay I was sleeping in became enormously large (like an aircraft hangar) and full of antiques; people walked around in deep conversation, fragments of which I overheard. Bizarrely, I knew that this was the product of medication and my mental state but I could not shake it off. In some respects I found it fascinating, particularly the conversations, which were tantalisingly cut short.

The overall experience, however, was not pleasant and I mentioned it to my consultant on ward rounds later that day. She decided to give me a sleeping tablet along with my other medications. The impact of this was remarkable. At the time of the operation I had not had an alcoholic drink for almost 12 months. The sleeping tablet had the same effect as two large glasses of red wine and very quickly. My contemporary recollection was that I did not sleep very much, but this is probably not the case. I did, however, have a distinct series of full blown hallucinations. Professionally, I am a medical educator and have an interest in simulation. My hallucination, which I acted out, had me running a real time simulation in the liver ward: all the patients, doctors, and nurses were participants and were following the outline of, but an unspecified, script which seemed to require them to do what they normally did. However, my recollection is that I observed (unspecified) suboptimal performance and decided to cut the simulation short, telling participants that we were going to resume at $613 \mathrm{am}$ (this time was quite specific). After a period of sleep (my bed had been moved to a new location), I awoke to find that the deadline had passed and nobody had restarted the simulation. I could not understand this and spent time watching someone construct a bar chart using tiny pieces of coloured paper and putting the end product in a window of the nurses' station. This experience had a profound and vivid effect on me and it represents the beginning of a major transition in my recovery.
As with the earlier hallucinations, I was aware that there were competing realities. Willingly "suspending disbelief," I was acting out the simulation and having conversations with the nursing staff, but with a realisation that there was another, more real, reality in the background, and occasionally I would occupy this mental space as I watched my invented reality unfold. In other words, part of me was observing the hallucination.

Following this, I became increasingly alert and engaged with an active process of recovery. I walked around the ward, did chair bound exercises, and took an active interest in ward life. I wrote a letter to the Guardian (which was published) about the need for more people to join the donor register.

I was discharged 10 days after my operation and continued a relatively quick recovery. I work from home for much of the time and I tentatively returned to my computer. I attended my first work related course in Manchester in mid-January and gave two lectures. By the end of the month I had my first full day course and by the end of February a three day course.

The diagnosis of a major illness is an important life event, particularly when the illness is symptom-free. Throughout the nine months from my diagnosis to the transplant I never felt ill and this made it easier to push the condition to one side and get on with normal life. In marked contrast, I was now someone with an illness, some minor symptoms, a significant drug regimen, and a long list of injunctions against what I could do and eat. Some of these made sense; others (sparkling bottled water but not still) made no sense at all.

I am, of course, still a transplantee and will be overseen by the liver transplant team at St James's hospital for the rest of my life. This is not a problem and I welcome its support and encouragement. The team's positive outlook and active engagement in my case feels incredibly supportive and mitigates any of the minor failings I experienced during my stay on the ward.

Competing interests: Both authors declare: no support from any organisation for the submitted work; no financial relationships with any organisations that might have an interest in the submitted work in the previous three years, no other relationships or activities that could appear to have influenced the submitted work

Provenance and peer review: Not commissioned; not externally peer reviewed.

Accepted: 27 June 2013

Cite this as: BMJ 2013;347:f4423

(c) BMJ Publishing Group Ltd 2013 


\section{A clinician's perspective}

Hereditary haemochromatosis is one of the commonest genetic disorders among white people. It causes abnormal iron metabolism, and the liver is often involved as it stores iron. Up to $97 \%$ of patients develop hepatic iron deposition, $10-25 \%$ hepatic fibrosis, and $4-6 \%$ cirrhosis. Progression of liver disease depends on the duration and severity of iron overload (ferritin level $>1000 \mu \mathrm{g} / \mathrm{L}$ ) and risk factors such as chronic viral hepatitis or alcohol misuse.

Patients with hereditary haemochromatosis are 20 times more likely to develop hepatocellular carcinoma. The risk is increased with alcohol intake, viral hepatitis, and advancing age. Hepatocellular carcinoma usually occurs in patients with cirrhosis although it can also occur in its absence. In women, childbirth and menstrual blood loss decrease excessive iron levels and may postpone the development of cirrhosis and liver cancer.

Orthotopic liver transplantation is indicated in patients with decompensated cirrhosis or hepatocellular carcinoma. The assessment of such patients involves multiple investigations and reviews by the medical, surgical, and anaesthetic teams. Each patient is then discussed at a multidisciplinary transplant meeting to decide whether they should go on the transplant waiting list. This decision is based on the severity of the underlying liver disease, the extent of cancer, and overall fitness of the patient. The Milan criteria are used to select suitable patients in terms of the hepatocellular carcinoma, whereas the MELD (Model End stage Liver Disease) and UKELD (United Kingdom End stage Liver Disease) scores assess the severity of liver disease. These are useful in determining prognosis and prioritising allocation of liver transplants.

While on the transplant list, patients with hepatocellular carcinoma often receive treatment for their tumour, such as radiofrequency ablation or transarterial chemoembolisation.

Patients stay in hospital for 10-14 days post-surgery, during which they are closely monitored and taught their new medications. After discharge they are followed up in the transplant clinic for life, focusing particularly on drug adherence and prevention of complications such as renal impairment, hypertension, diabetes mellitus, and obesity, which help to ensure long term survival.

Phaedra Tachtatzis, consultant hepatologist

\section{Useful resources for patients and health professionals www.britishlivertrust.org.uk}

Canadian Liver Foundation (www.liver.ca)—-provides support for research and education into the causes, diagnoses, prevention, and treatment of all liver diseases

Australian Liver Foundation (www.liver.org.au)—dedicated to the prevention, control, and cure of diseases of the liver, gallbladder, and bile ducts

European Association for the Study of the Liver (www.easl.eu)—promotes research into liver disease, supporting wider education and change in European liver policy

American Association for the Study of Liver Disease (www.aasld.org/Pages/Default.aspx)—committed to preventing and curing liver disease

American Liver Foundation (www.liverfoundation.org)—facilitates, advocates, and promotes education, support, and research for the prevention, treatment, and cure of liver disease 